\title{
Structural Evolution Mechanisms of Biochar from Solid State Fermentation Residues in a Novel V-shaped Down- tube Reactor during Fast Pyrolysis
}

\author{
Xiajin Ren, ${ }^{\mathrm{a}, \mathrm{b}}$ Juanjuan Wu, ${ }^{\mathrm{a}, \mathrm{b}}$ Donghong Zhang, ${ }^{\mathrm{a}, \mathrm{b}}$ Hang Xu, ${ }^{\mathrm{a}, \mathrm{b}}$ Hongzhen Cai, ${ }^{\mathrm{a}, \mathrm{b}, *}$ and \\ Xiaona Lin ${ }^{\mathrm{a}, \mathrm{b}, *}$
}

The structural changes of biochar prepared from sweet sorghum bagasse during fast pyrolysis of 200 to $700{ }^{\circ} \mathrm{C}$ in a novel V-shaped down-tube reaction device was investigated by ultimate analysis, bomb calorimeter, Fourier transform infrared spectroscopy, X-ray diffraction, scanning electron microscopy, and $\mathrm{N}_{2} / \mathrm{CO}_{2}$ adsorption methods. The results showed that the pyrolysis temperature had an important effect on the composition and physicochemical properties of sweet sorghum bagasse biochar. With the increase of pyrolysis temperature, the yield of biochar and the polar functional groups decreased, but the higher heating values and mineral salts increased. However, the surface area, pore volume, and adsorption $\left(\mathrm{N}_{2}, \mathrm{CO}_{2}\right)$ increased first and then decreased. The biochar obtained at 500 ${ }^{\circ} \mathrm{C}$ had the most developed pore structures. The experimental results shed light on the high-quality utilization of sweet sorghum bagasse obtained from advanced solid-state fermentation.

Keywords: Sweet sorghum bagasse; V-shaped down tube reactor; Fast pyrolysis; Biochar; Characterization

Contact information: a: School of Agricultural Engineering and Food Science, Shandong University of Technology, Zibo, P.O. Box 255049, China; b: Shandong Research Center of Engineering and Technology for Clean Energy, Zibo, P. O. Box 255049, China;

*Corresponding author: chzh666666@126.com; Linxiaona1120@163.com

\section{INTRODUCTION}

Currently, fossil energy is depleting, and the environmental pressure is becoming increasingly serious. In contrast, as one of the major clean, low-carbon renewable energy sources, the development and utilization of biomass energy has received increasing attention in the world (Boakye-Boaten et al. 2016). For example, agricultural and forestry wastes such as sweet sorghum stalk (Junshe and Ping 2007) is considered to be an ideal raw material for fuel ethanol because of its high sugar content. At present, fuel ethanol is recognized as the most mature gasoline substitute in the world. As a clean fuel, fuel ethanol plays a significant role in saving resources, reducing air pollution, and reducing greenhouse gas emissions (Ma et al. 2016). There are two main technologies for producing fuel ethanol: liquid state fermentation (LSF) and solid-state fermentation (SSF). The LSF approach employs traditional and mature technology, with the fermentation of extracted sweet sorghum stem juice. The SSF approach carries out the fermentation with crushed sweet sorghum stalk powder. This could simplify the production process and improve the yield of fuel ethanol compared to LSF. In addition, the advanced solid-state fermentation (ASSF) (Li et al. 2013) technology developed by Tsinghua University has realized a highly efficient clean conversion and automatic control of ethanol from sweet sorghum stalk. 
However, it generated a lot of sweet sorghum bagasse (SSB) in the fermentation process. In addition to a small portion used in feed (Houx et al. 2013) and papermaking (Fatriasari and Iswanto 2015), most of the bagasse has been disposed of as waste, which has a negative impact on the environment and resources. Hence, an environmentally friendly technology is needed for the clean and efficient utilization of SSB.

As one of the most potential biomass energy technologies, biomass fast pyrolysis technology has made significant progress due to the high adaptability in utilizing a variety of biomass feedstock. Moreover, the chemical compositions of SSB mainly contain cellulose, hemicellulose, and lignin, and the $\mathrm{C} / \mathrm{H}$ ratio is relatively high. So sweet sorghum bagasse can be converted into a high-value product by fast pyrolysis technology. The biomass fast pyrolysis technology is a new biomass energy utilization technology that converts low energy density biomass into high energy density products (non-condensable gas, bio-oil, and biochar) (Chen et al. 2016). It is known that the non-condensable gas can be used for power generation and heating, the bio-oil can be used independently or mixed with fossil fuels in boilers for heat and power generation, and it can also be directly applied to gas turbines as the fuel (Abnisa and Daud 2014).

Previous researchers mainly have studied the properties of bio-oil obtained by the fast pyrolysis of SSB, but the addition product (biochar) has been rarely studied. It is worth noting that biochar has wide application prospects in many areas due to its versatile physicochemical characteristics (Zhang et al. 2017). For example, biochar can be used to improve soil as a soil amendment and treat sewage as an adsorbent (ThangalazhyGopakumar et al. 2015), and its high heating value can be applied in energy production (Nanda et al. 2016). What's more, biochar also can be used for activated carbon production, catalyst precursor, carbon sequestration, and so on (Alvarez et al. 2014; Chen et al. 2015; Rafiq et al. 2016). However, whether biochar can be used effectively depends on its basic properties, which are mainly affected by materials and pyrolysis conditions. The structural evolution of biochar also plays an important role in the biomass thermochemical conversion process. The change of the internal structure of biochar particles not only affects its physical and chemical properties, but it also determines its reactivity and conversion rate (Fatehi and Bai 2017). Recently a large number of scholars have studied the effects of biomass feedstock or pyrolysis conditions (pyrolysis temperature, heating rate, residence time, and pressure) on the structure and reaction characteristics of biochar (Angin 2013; Zhang et al. 2015), but there have been few studies on the evolution of biochar structural features during fast pyrolysis. The evolution of biochar structure during the fast pyrolysis process is critical for the practical application of biochar, and this aspect remains a topic worth exploring.

In general, reaction devices for the production of biochar mainly include fixed beds (Tan et al. 2017) and fluidized beds (Chen et al. 2011). Among them, the fluidized bed has been expanded to an industrial scale due to its simple structure and simple operation compared with others. The disadvantage is that it needs to introduce a large amount of fluidizing gas, which greatly increases the cost. However, the novel V-shaped down tube (VDT) reaction device developed by the authors' group for the production of bio-oil exhibits absolute advantages ( $\mathrm{Li}$ et al. 2017). The descending tube of VDT is V-shaped, and the heat preservation sleeve tube is placed on the outer wall of the tube, which reduces the overall height of the test device. Specifically, fast pyrolysis is completed by directly heating biomass particles with heat carrier (ceramic balls) without introducing any carrier gas, which reduces the heat loss and the cost. To date, there still has been little study on the evolution of biochar during the fast pyrolysis process of SSB by VDT. 
Yin et al. (2013) used the fluidized bed for fast pyrolysis to produce bio-oil, and the gas chromatography-mass spectrometry (GC-MS) analysis showed an annulation feature of bio-oil compositions produced from SSB. Naik et al. (2017) performed fast pyrolysis experiments in a laboratory-scale vertical fixed bed reactor using SSB as raw materials; the results showed that the calorific value of sorghum bagasse bio-oil was in a comparable range with other bio-oils. Unlike these, the SSB after ASSF was used to conduct fast pyrolysis to produce sweet sorghum bagasse biochar (SSBB) in the novel VDT reaction device within a wide temperature range of 200 to $700{ }^{\circ} \mathrm{C}$. The evolution of SSBB structural features was explored in the present study. This work would be important in helping to understand the properties of biochar obtained in the novel VDT reactor and can provide the basis for effective utilization of biochar.

\section{EXPERIMENTAL}

\section{Materials}

As the feedstock for fast pyrolysis, the SSB obtained from ASSF was crushed and then sieved to keep them at less than $1 \mathrm{~mm}$ in size. The main properties of SSB were tested on a dry basis. The proximate analysis of SSB was measured in a muffle furnace, the chemical composition of SSB was investigated in an semi-automatic fiber analyzer (FIWE6; VELP Co., Usmate, Italy), and the thermal properties of SSB were evaluated in a thermogravimetric analyzer (TGA) (STA 499 F5; Netzsch, Selb, Germany).

\section{The VDT Pyrolysis System and Pyrolysis Experiments}

As shown in Fig. 1, the VDT pyrolysis system is mainly composed of a feeding device, VDT reactor, separator, condenser, heat carrier circulating device, and data acquisition. The most distinctive feature of the essential design characteristics is the ceramic balls acting as heat carriers, and the SSB mixing feedstocks with ceramic balls can heat SSB rapidly in the reactor, exhibiting a high heating efficiency. The pyrolysis experiment was conducted after debugging and confirming that the operation was normal. Moreover, there are many advantages in the VDT pyrolysis system, such as its ease of operating, ease of maintenance, and suitability to be popularized and applied, compared to other pyrolysis systems. The utilization of VDT pyrolysis system not only improved the energy efficiency but it also ensured the continuity of pyrolysis.

Prior to the experimental runs, the heat carrier circulating device was preheated by the ceramic balls until thermal equilibrium was reached in the pyrolysis system, and then the SSB feedstocks were fed to the pyrolysis reactor continuously at a $100 \mathrm{~kg} / \mathrm{h}$ constant cycle rate after the ceramic balls reached the required temperature. The final temperatures of pyrolysis experiments were set within the range 200 to $700{ }^{\circ} \mathrm{C}$. The different biochar samples were captured in a separator. After each pyrolysis experiment, the collected SSBB was placed in a dryer to dry for the subsequent characterization and analysis. The study of bio-oil and biogas obtained by the VDT pyrolysis system has been explored in previous work (Fu et al. 2019). The main novelty of this study is to explore structural evolution mechanisms of biochar in a novel V-shaped down tube reactor during fast pyrolysis of SSB, which was obtained by solid-state fermentation. The results could be helpful to utilize the high-value solid-state fermentation residues. 


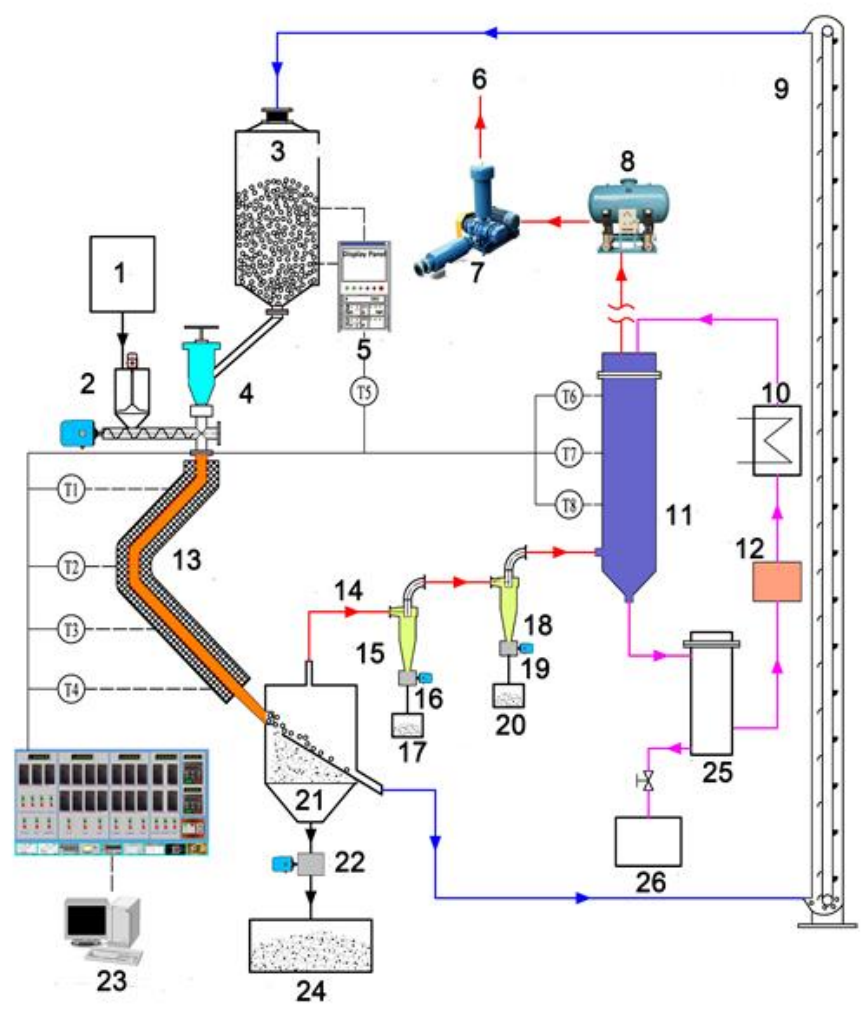

Fig. 1. The VDT pyrolysis system: 1. Biomass; 2. Biomass feeder; 3. Heat carrier heater; 4 . Heat carrier flow; 5 . Temperature control regulator; 6 . Non condensable gas; 7 . Induced draft fan; 8. Pressure regulator lank; 9. Bucket elevator; 10. Plate heat exchanger; 11. Spray condenser; 12. Oil pump; 13. V-shaped down tube reactor; 14. Pyrolysis vapors; 15. Cyclone-1; 16. Valve-2; 17. Fine particles canister; 18. Cyclone-2; 19. Valve-3; 20. Fine particles canister; 21. Gas-solid separator; 22. Valve-1; 23. Data acquisition/control system; 24. Char collector; 25. Bio-oil filter; 26. Bio-oil tank; T1. Temperature1; T2. Temperature2; T3. Temperature3; T4. Temperature4; T5. Temperature5; T6. Temperature6; T7. Temperature7; T8. Temperature8. The device diagram was obtained from previous work by the authors' group (Fu et al. 2017).

\section{Methods}

\section{Characterization and analysis of SSBB}

The ultimate analysis and the higher heating values (HHVs) of the feedstock and SSBB were evaluated using an elemental analyzer (model EA 3000; Euro Vector, Pavia, Italy) and a C2000 bomb calorimeter (model C2000; IKA, Staufen, Germany). The Fourier transform infrared (FTIR) (Nicolet5700; Thermo Fisher, Waltham, MA, USA) spectra were measured with $\mathrm{KBr}$ method. The X-ray diffraction (XRD) patterns were determined by a polycrystalline X-ray diffractometer (AXS D8 Advance; Bruker, Karlsruhe, Germany) using $\mathrm{CuK} \alpha$ radiation with $2 \theta$ ranging between $5^{\circ}$ and $40^{\circ}$ at $5^{\circ} \mathrm{min}$. The pore characteristics were tested using an automatic specific surface analyzer (ASAP 2020; Micromeritics Instrument, Norcross, GA, USA). The scanning electron microscope (SEM) (Sirion 200; FEI, Hillsboro, OR, USA) was used to observe the microstructure, and the powder samples were sputtered with gold prior to processing to avoid electrical charging during examination. The pore structure characteristics were investigated with a surface area and porosity analyzer (ASAP 2060M; Micromeritics Instrument, Norcross, GA, USA), and $\mathrm{N}_{2}$ and $\mathrm{CO}_{2}$ were used as the adsorption gases. 


\section{RESULTS AND DISCUSSIONS}

\section{Feedstock (SSB) Characterization}

Table 1 presents the main properties of SSB. The content of volatile matter in SSB was the highest $(78.2 \mathrm{wt} \%)$, the content of ash was the lowest $(4.75 \mathrm{wt} \%)$, and the remainder was fixed carbon $(17.0 \mathrm{wt} \%)$ by the proximate analysis. In addition, the ultimate analysis revealed that the elements of SSB were composed of carbon, hydrogen, nitrogen, and oxygen, and the amounts of the elements were 45.7, 6.05, 0.51, and $47.8 \mathrm{wt} \%$, respectively. The chemical compositions of SSB are also presented in Table 1 and show that the content of cellulose was the highest with a value of $36.7 \mathrm{wt} \%$, while the respective contents of hemicelluloses and lignin were 23.3 and $17.1 \mathrm{wt} \%$, respectively. The abovementioned properties of SSB were consistent with those of other studies (Cardoso et al. 2011; Yin et al. 2013), except for minor differences that were attributed to the differences in geographical location and cultivation status. It is worth noting that there was a big difference of the main properties between SSB and sweet sorghum straw that can be ascribed to the effect of ASSF.

Table 1. The Main Properties of SSB

\begin{tabular}{|c|c|}
\hline \multicolumn{2}{|c|}{ Proximate Analysis (wt\%) } \\
\hline Volatile matter & 78.24 \\
\hline Fixed carbon & 17.01 \\
\hline Ash & 4.75 \\
\hline \multicolumn{2}{|c|}{ Ultimate Analysis (wt\%) } \\
\hline C & 45.68 \\
\hline $\mathrm{H}$ & 6.05 \\
\hline $\mathrm{N}$ & 0.51 \\
\hline $\mathrm{O}$ & 47.76 \\
\hline \multicolumn{2}{|c|}{ Chemical Composition (wt\%) } \\
\hline Cellulose & 36.67 \\
\hline Hemicelluloses & 23.26 \\
\hline Lignin & 17.13 \\
\hline
\end{tabular}

Likewise, the thermal behavior of SSB was investigated by TGA at the heating rate of $10{ }^{\circ} \mathrm{C} / \mathrm{min}$ over a range from 35 to $800{ }^{\circ} \mathrm{C}$. Generally speaking, the weight loss of biomass is mainly caused by the release of volatiles during pyrolysis. With the increase of heating temperature, the macromolecules in the biomass could absorb a large amount of heat, resulting in a series of parallel and continuous chemical reactions of biomass principal components among cellulose, hemicellulose, and lignin, which results in the release of volatiles. As shown in Fig. 2, the whole pyrolysis process included four stages. The first stage (the drying stage, $<100^{\circ} \mathrm{C}$ ) was mainly the process of losing water from raw SSB feedstock. A weak peak was visible on the derivative thermogravimetric (DTG) curve, showing a certain degree of weight loss. The moisture in biomass was vaporized when the temperature was approximately $100^{\circ} \mathrm{C}$. In the second stage (the preheating stage, 100 to $200{ }^{\circ} \mathrm{C}$ ), no remarkable changes were observed on the TG curve. The third stage (the devolatilization stage, 200 to $400{ }^{\circ} \mathrm{C}$ ) was the main stage of SSB during the pyrolysis process, and most of the weight loss of SSB occurred at this stage. At this temperature range, SSB was cracked into small molecular weight gases and condensable volatiles of macromolecules, which was the main cause of weight loss. Two peaks could be seen in this stage. The peak shoulder that occurred at $270{ }^{\circ} \mathrm{C}$ was mainly caused by the pyrolysis 
of hemicellulose, and the sharpest peak occurred at approximately $300{ }^{\circ} \mathrm{C}$, which was caused by the pyrolysis of cellulose in the SSB feedstock. Hemicellulose is an amorphous polymer with relatively low molecular weight and low degree of polymerization (Ma et al. 2015), so the thermal stability of hemicellulose is lower than cellulose and the pyrolysis of hemicellulose takes place earlier than that of cellulose. In terms of the fourth stage (carbonization stage, $>400{ }^{\circ} \mathrm{C}$ ), slow pyrolysis and carbonization of lignin in SSB feedstock occurred, and the biochar was eventually formed. Lignin has better thermal stability compared to hemicellulose and cellulose because of its more highly crosslinked and branched structures (Ma et al. 2015), which made the pyrolysis and carbonization of lignin occur at higher temperatures.

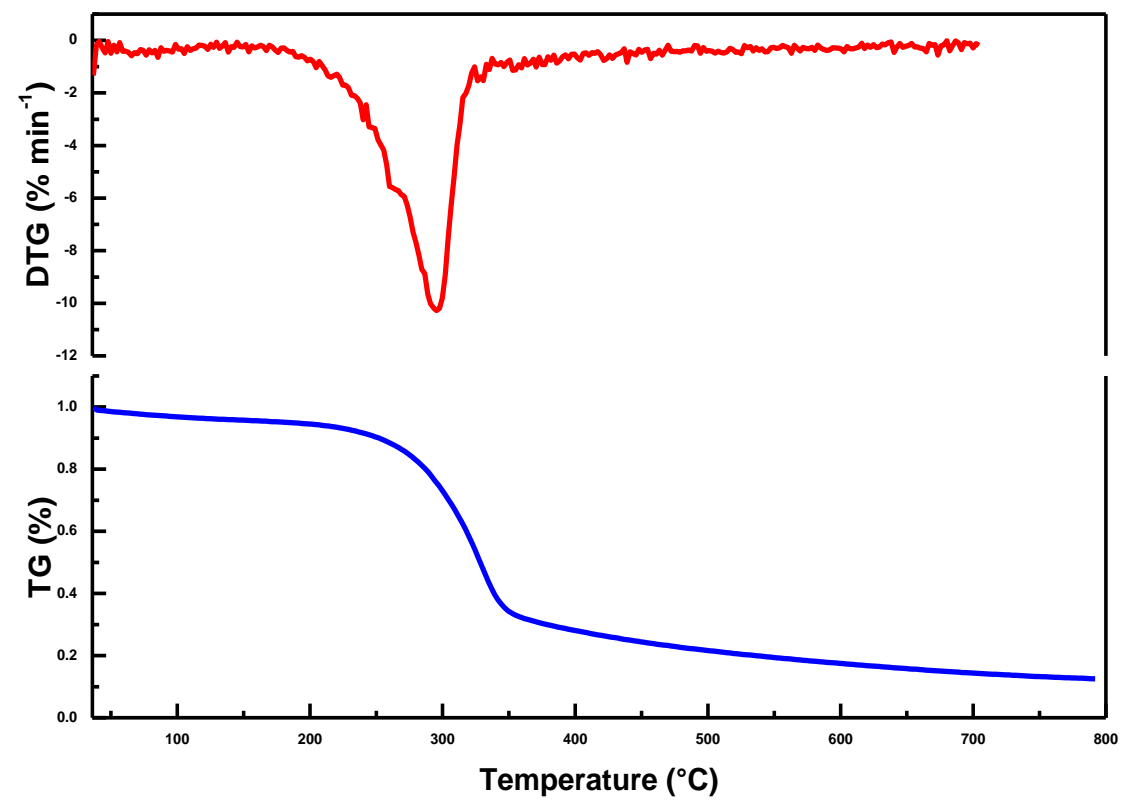

Fig. 2. $D T G$ and $T G$ curves of $S S B$ at the heating rate of $10^{\circ} \mathrm{C} / \mathrm{min}$

Antal and Varhegyi (1995) thought that the volatilization of biomass pyrolysis could be analyzed under the assumption that the pyrolysis process of cellulose and hemicellulose did not affect each other. Based on this assumption, a conclusion could be drawn that the weight loss peak in the lower temperature region was the pyrolysis of hemicellulose, the weight loss peak in the relatively high-temperature region was the pyrolysis of cellulose, while the pyrolysis of lignin occurred slowly in a wide temperature range. In other words, the pyrolysis process of biomass is the superposition of three pyrolysis process of organic components including cellulose, hemicellulose, and lignin. In particular, it should be noted that biomass is a multicomponent substance, so the decomposition of the different components is bound to occur at the same time more or less. Hence, the changes in the DTG curve can only represent the decomposition of major components. 


\section{Biochar (SSBB) Characterization}

Physicochemical properties

The increase of pyrolysis temperature is bound to lead to the decomposition and recombination of the internal structure of SSB, which could change the physicochemical properties of biochar. Table 2 shows the physicochemical properties of SSBB at different temperatures including the ultimate analysis, HHV, and yield of the biochar. The increase of pyrolysis temperature led to the increase of carbon contents and the decrease of hydrogen contents and oxygen contents. It is clear that the carbon content increased $61.0 \%$, while the hydrogen and oxygen contents decreased $76.9 \%$ and $49.4 \%$, respectively, over a temperature range from ambient temperature to $700{ }^{\circ} \mathrm{C}$. As an important index for the analysis of polymer elements, the ratios of $\mathrm{H} / \mathrm{O}$ and $\mathrm{O} / \mathrm{C}$ have been used widely to determine the aromatization structure and composition of the polymer. As shown in Table 2 , with the increment of the pyrolysis temperature, the $\mathrm{H} / \mathrm{O}$ and $\mathrm{O} / \mathrm{C}$ ratios were decreased by $85.5 \%$ and $68.0 \%$, respectively. This results are consistent with those for other biomass (Fu et al. 2012), and there was a remarkable negative correlation between the values of $\mathrm{H} / \mathrm{O}$ and $\mathrm{O} / \mathrm{C}$ of biochar and pyrolysis temperature $(\mathrm{p}<0.01)$. The decreases of the above results were mainly due to the aggravation of dehydrogenation and deoxidation reactions during the heating process. It also has been shown that the increase of temperature could promote the fracture of weak chemical bond and formation of condensation products, and that biochar prepared at higher temperature is more stable (Spokas et al. 2010). Additionally, the SSB had a high HHV of $18.3 \mathrm{MJ} / \mathrm{Kg}$, far more than that of corn stalk (16.8 MJ/Kg) (Fu et al. 2018), and the HHV increased by $65.0 \%$, reaching a maximum of $30.2 \mathrm{MJ} / \mathrm{Kg}$ as the temperature was raised to $700{ }^{\circ} \mathrm{C}$. The high $\mathrm{HHV}$ provided the possibility for the application of biochar in biofuels and energy production. Other than that, the pyrolysis temperature is of great importance to the yield of the biochar. As shown in Table 2, the yield of SSBB sharply decreased with the increase of pyrolysis temperatures, especially when the pyrolysis temperature raised from 300 to $400{ }^{\circ} \mathrm{C}$. When the pyrolysis temperature exceeded $500{ }^{\circ} \mathrm{C}$, the decrease of SSBB yield gradually slowed down. The decrease of SSBB yield may be related to the greater primary decomposition and the secondary decomposition of the biochar (Fu et al. 2012). In summary, proper selection of pyrolysis temperature can improve the composition and energy characteristics of SSB, and then improve the practical applications of SSB.

Table 2. The Ultimate Analysis, HHV, and Yield of the Biochar at Different Temperatures

\begin{tabular}{|c|c|c|c|c|c|c|c|c|}
\hline $\mathbf{T}\left({ }^{\circ} \mathbf{C}\right)$ & $\begin{array}{c}\mathbf{C} \\
(\mathbf{w t} \%)\end{array}$ & $\begin{array}{c}\mathbf{H} \\
(\mathbf{w t} \%)\end{array}$ & $\begin{array}{c}\mathbf{N} \\
(\mathbf{w t} \%)\end{array}$ & $\begin{array}{c}\mathbf{O} \\
(\mathbf{w t} \%)\end{array}$ & $\mathbf{H} / \mathbf{C}$ & $\mathbf{O} / \mathbf{C}$ & $\begin{array}{c}\mathbf{H H V} \\
(\mathbf{J} / \mathbf{k g})\end{array}$ & $\begin{array}{c}\text { Yield } \\
(\mathbf{\%})\end{array}$ \\
\hline SSB & 45.68 & 6.05 & 0.51 & 47.76 & 1.59 & 0.78 & 18.27 & -- \\
\hline 200 & 46.03 & 5.97 & 0.54 & 47.46 & 1.56 & 0.77 & 19.82 & 95.1 \\
\hline 300 & 50.61 & 5.61 & 0.59 & 43.19 & 1.33 & 0.64 & 23.19 & 78.62 \\
\hline 400 & 65.09 & 4.31 & 0.96 & 29.64 & 0.79 & 0.34 & 27.93 & 35.81 \\
\hline 500 & 68.67 & 3.17 & 0.74 & 27.42 & 0.55 & 0.30 & 28.47 & 28.23 \\
\hline 600 & 73.07 & 2.04 & 0.69 & 24.20 & 0.34 & 0.25 & 29.87 & 25.72 \\
\hline 700 & 73.54 & 1.4 & 0.64 & 24.18 & 0.23 & 0.25 & 30.15 & 24.04 \\
\hline
\end{tabular}

\section{FTIR analysis}

To determine the effects of pyrolysis temperature on the surface functional groups of biochar, FTIR spectroscopy was performed on the samples over a scanning range from $4000 \mathrm{~cm}^{-1}$ to $400 \mathrm{~cm}^{-1}$ with a resolution of $4 \mathrm{~cm}^{-1}$. As shown in Fig. 3 and Table 3, the 
broad and strong peak at $3400 \mathrm{~cm}^{-1}$ was attributed to the asymmetrical $\mathrm{O}-\mathrm{H}$ stretching vibration that was caused by phenolic hydroxyl and alcohol hydroxyl. The peaks at 2920 and $2850 \mathrm{~cm}^{-1}$ were due to the $\mathrm{C}-\mathrm{H}$ stretching vibration that was caused by aliphatic structures, and the $\mathrm{C}-\mathrm{H}$ bending vibration at $1374 \mathrm{~cm}^{-1}$ was caused by the aliphatic structures equally. The peaks at $1710 \mathrm{~cm}^{-1}$ were caused by the carbonyl $\mathrm{C}=\mathrm{O}$ stretching vibration. Likewise, the absorption peaks at 1636 and $1513 \mathrm{~cm}^{-1}$ were attributed to the aromatic $\mathrm{C}=\mathrm{C}$ stretching vibration with olefinic and aromatic structures. The $\mathrm{C}-\mathrm{O}$ stretching vibration with unsaturated ethers, tertiary hydroxyl, and primary hydroxyl was responsible for the peaks at 1246,1162, and $1052 \mathrm{~cm}^{-1}$. Additionally, the phenol structures may cause the $\mathrm{O}-\mathrm{H}$ out of plane deformation to appear at $608 \mathrm{~cm}^{-1}$. Typically, the pyrolysis temperature could affect the chemical structure of biochar remarkably. As shown in Fig. 3, there was a large difference in functional groups on the surface of biochars obtained from different pyrolysis temperatures. With the increase of pyrolysis temperatures, the $\mathrm{O}-\mathrm{H}$ groups at $3400 \mathrm{~cm}^{-1}$ decreased gradually and the higher the temperature, the less the $\mathrm{O}-\mathrm{H}$ groups, indicating that the increment of the pyrolysis temperature could effectively reduce the polarity of SSB. Moreover, the intensity of C-H stretching vibration at 2920 and 2850 $\mathrm{cm}^{-1}$ was also weaker compared with SSB feedstock, which showed that the dehydrogenation and deoxidation reactions were also gradually intensified and the aromatization of SSBB was increased gradually. Furthermore, except the above functional groups shown at 3400,2920 , and $2850 \mathrm{~cm}^{-1}$, the other functional groups marked in Fig. 3 gradually decreased or even disappeared, as the temperature exceeded $300{ }^{\circ} \mathrm{C}$. Especially when the temperature reached $700{ }^{\circ} \mathrm{C}$, the absorption peaks of all carbon-containing functional groups of biochar disappeared, and this was consistent with the results of relevant scholars who thought that the FTIR spectra of biochar under $700{ }^{\circ} \mathrm{C}$ was similar to that of pure graphite (Keiluweit et al. 2010; Uchimiya et al. 2011).

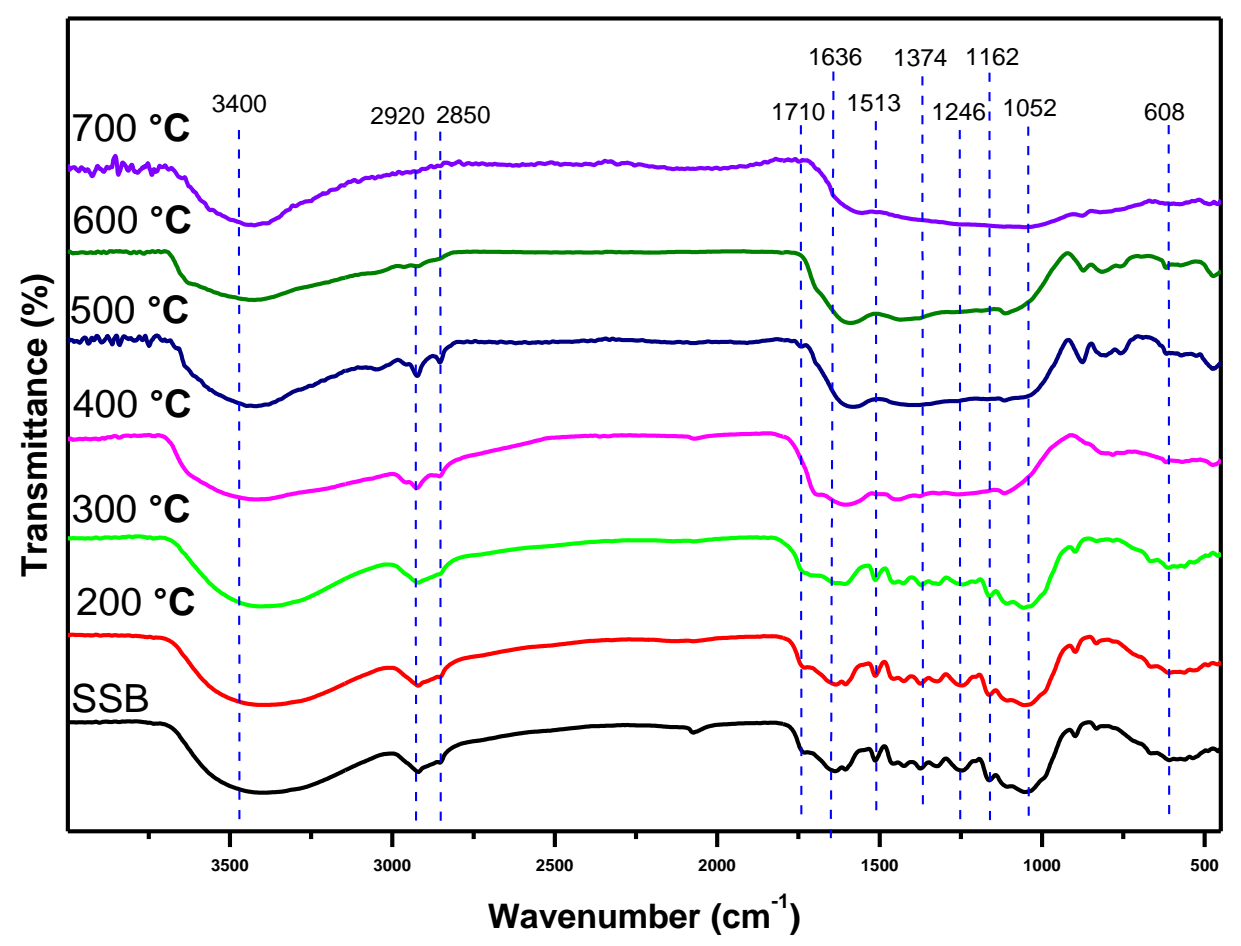

Fig. 3. FTIR spectra of SSB and the SSBB prepared at different temperatures 
Table 3. Functional Groups of SB and the SSBB Prepared at Different Temperatures

\begin{tabular}{|c|c|c|}
\hline Wavenumber $\left(\mathbf{c m}^{-1}\right)$ & Infrared Absorption & $\begin{array}{c}\text { Atomic Groups and } \\
\text { Structures }\end{array}$ \\
\hline 3400 & O-H stretching & Hydroxyl \\
\hline 2920 & C-H stretching & Aliphatic structures \\
\hline 2850 & C-H stretching & Aliphatic structures \\
\hline 1710 & $\mathrm{C}=\mathrm{O}$ stretching & Carbonyl \\
\hline 1636 & $\mathrm{C}=\mathrm{C}$ stretching & Olefinic structures \\
\hline 1513 & $\mathrm{C}=\mathrm{C}$ stretching & Aromatic structures \\
\hline 1374 & C-H bending & Aliphatic structures \\
\hline 1246 & C-O stretching & Unsaturated ethers \\
\hline 1162 & C-O stretching & Tertiary hydroxyl \\
\hline 1052 & C-O stretching & Primary hydroxyl \\
\hline 608 & O-H out of plane deformation & Phenol structures \\
\hline
\end{tabular}

\section{$X R D$ analysis}

From the above FTIR analysis, it was shown that the increment of the temperature increased the degree of aromatization and thermal stability of the biochar, while the thermal stability of biochar was related to the development of carbon microcrystal structure. To further investigate the effect of temperature on the crystal structure of biochar, the SSB and SSBB were characterized by X-ray diffraction; and the XRD patterns are presented in Fig. 4. At $d=5.80$ and $3.89 \AA$ in SSB feedstock, two main peaks showed consistency with that of 200 and $300^{\circ} \mathrm{C} \mathrm{SSBB}$. The two peaks were attributed to the crystal structure of cellulose (Kim et al. 2012; Al-Wabel et al. 2013).

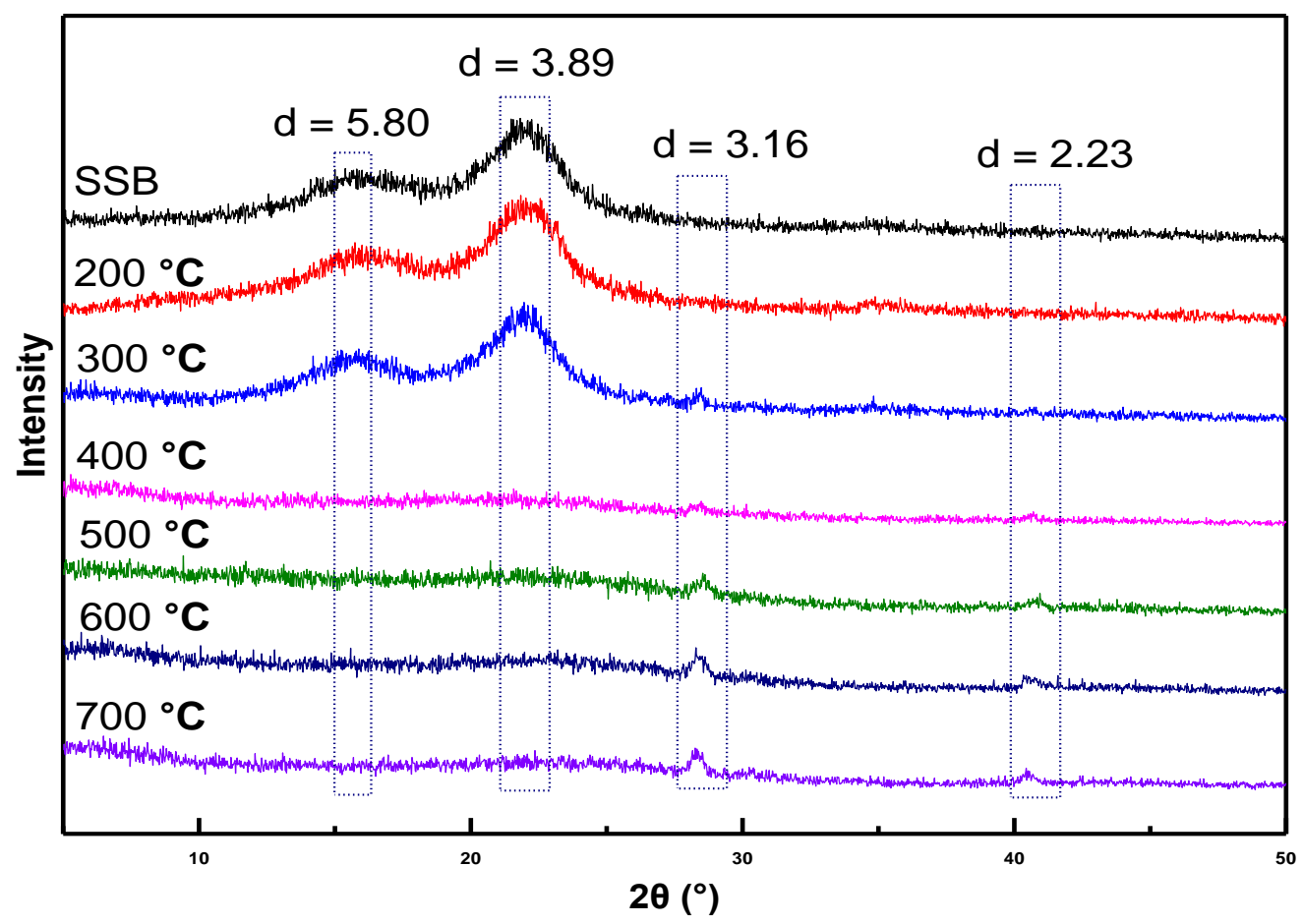

Fig. 4. XRD patterns of SSB and the SSBB prepared at different temperatures 
It should be noted that both peaks disappeared at higher temperatures (400 to 700 ${ }^{\circ} \mathrm{C}$ ), which showed that the microcrystalline structure of cellulose was destroyed and decomposed, which was consistent with the conclusion of DTG analysis of SSB in Fig. 2. At this time, the biochar was amorphous. Likewise, many scholars have reached the same conclusion. Kloss et al. (2012) prepared four biochars (wheat straw, poplar wood, spruce wood, and needle mixture) with slow pyrolysis, and the XRD analysis showed that the characteristic peak of cellulose disappeared at a higher temperature. Wang et al. (2009) came to the same conclusion that the cellulose peaks of pine wood biochar vanished as the temperature reached and exceeded $400{ }^{\circ} \mathrm{C}$, but it was present in $300{ }^{\circ} \mathrm{C}$ pine wood biochar. In contrast, two main peaks at $d=3.16$ and $2.23 \AA$ caused by a $\mathrm{KCl}$ mineral (Yuan et al. 2011) uninterruptedly appeared over a temperature range from 300 to $700{ }^{\circ} \mathrm{C}$, and a higher temperature resulted in sharper peaks. The increment of temperature led to the gradual enrichment of KCI crystals in SSBB. In addition, the intensity of all the samples decreased with the increment of the temperature, which proved again that the biochar prepared at a higher temperature had better thermal stability. Kotaiah Naik et al. also found the enrichment of mineral components in biochar because of the increase of temperature (Naik et al. 2017).

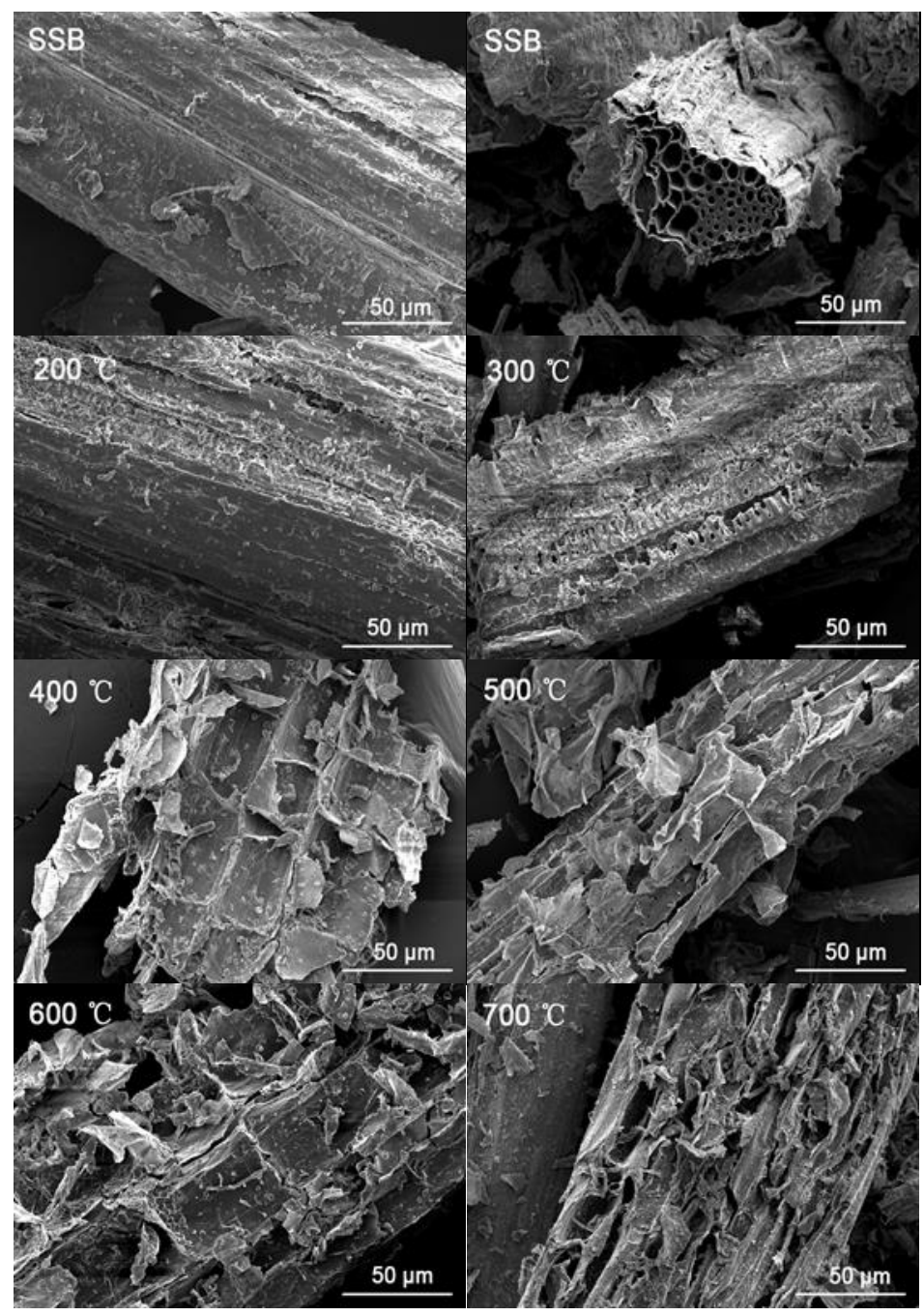

Fig. 5. SEM images of SSB and the SSBB prepared at different temperatures at the magnification of 2000) 


\section{SEM analysis}

Scanning electron microscopy was used to detect the microstructure of biochar based on the interaction of electrons and matter. Figure 5 presents the morphology of SSB and the SSBB prepared under different pyrolysis temperatures at a magnification of 2000. The two images of SSB showed a columnar fiber bundle structure (Zhang et al. 2011) that was smooth. There were no holes or damage on the surface of SSB. Through comparing the SEM images of SSB and SSBB, it was observed that the surface of SSB was changed remarkably by the change of the pyrolysis temperature.

Although there were only slight differences between SSB and SSBB at $200{ }^{\circ} \mathrm{C}$, it was still observed that the surface was cracked and roughened. Further, tiny pore structures were clearly observed from the image of $300^{\circ} \mathrm{C} \mathrm{SSBB}$, which was attributed to the release of volatile gases in SSB. As the pyrolysis temperature reached $400{ }^{\circ} \mathrm{C}$, the number of pores increased obviously, and the pore structure of SSBB was more compact and regular, which was attributed to the further decomposition of organic matter.

When the temperature was increased to $500{ }^{\circ} \mathrm{C}$, the pore structure of SSBB was developed completely. The image of $600{ }^{\circ} \mathrm{C} \mathrm{SSBB}$ showed some cracks and breakages that may be resulted from the violent release of volatile species, and the original skeleton structure could not be maintained. When the pyrolysis temperature was further increased to $700{ }^{\circ} \mathrm{C}$, the fracture on the surface of SSBB was more serious. The skeleton structure of SSBB collapsed and the pore structure became blurred. In addition, due to the enrichment of the ash in SSB with increased temperature, some small solid particles attached to the surface of SSB (Sharma et al. 2004).

\section{Pore structure characteristics analysis}

Apart from the analyses described above, it is imperative to investigate the pore structure characteristics of SSBB under different pyrolysis temperatures. As shown in Table 4 , the increase of the pyrolysis temperature had an important effect on the surface area and pore volume of SSBB. When the pyrolysis temperature was $200{ }^{\circ} \mathrm{C}$, the main manifestation was the loss of water and the mass decomposition of organic matter had not yet occurred, which could explain the similar characteristics of porosity between the SSB and $200{ }^{\circ} \mathrm{C}$ SSBB.

As the temperature further rose to $300{ }^{\circ} \mathrm{C}$, the specific surface area of SSBB increased to $3.35 \mathrm{~m}^{2} / \mathrm{g}$, which may have been because the release of volatile substances and the precipitation of volatile products caused by the decomposition of hemicellulose. Such processes could have led to the opening of a few pores. As the pyrolysis temperature exceeded $400{ }^{\circ} \mathrm{C}$, the specific surface area of SSBB increased dramatically and reached the maximum of $17.3 \mathrm{~m}^{2} / \mathrm{g}$ at $500{ }^{\circ} \mathrm{C}$. The sharp increase of the specific surface area was mainly ascribed to the increase of micropores, which may be attributed to the mass decomposition of volatiles, especially cellulose.

A related study showed that the decomposition of cellulose occurred at 250 to 450 ${ }^{\circ} \mathrm{C}$ (Vamvuka \& Sfakiotakis, 2011), which was consistent with the results of this study. As also shown in Table 4, when the pyrolysis temperature reached 600 or even $700{ }^{\circ} \mathrm{C}$, the pore structure characteristics of SSBB showed a sharp downward trend over a range from 17.33 to $4.95 \mathrm{~m}^{2} / \mathrm{g}$. This was because the excessive pyrolysis temperature that led to a more intense pyrolysis reaction caused the coalescence, closure, even the melting, and collapse of the pores. 
Table 4. Surface Area and Pore Volume of SB and the SSBB Prepared at Different Temperatures

\begin{tabular}{|c|c|c|c|c|c|}
\hline $\boldsymbol{T}\left({ }^{\circ} \mathbf{C}\right)$ & SBET $\left(\mathbf{m}^{\mathbf{2}} / \mathbf{g}\right)$ & $\boldsymbol{V}_{\text {mic }}\left(\mathbf{c m}^{\mathbf{3}} / \mathbf{g}\right)$ & $\boldsymbol{V}_{\text {mes }}\left(\mathbf{c m}^{\mathbf{3}} / \mathbf{g}\right)$ & $\boldsymbol{V}_{\text {total }}\left(\mathbf{c m}^{\mathbf{3}} / \mathbf{g}\right)$ & $\boldsymbol{V}_{\text {mic }} / \boldsymbol{V}_{\text {total }}(\mathbf{\%})$ \\
\hline SSB & 2.1561 & 0.000162 & 0.001024 & 0.002915 & 5.56 \\
\hline 200 & 2.1976 & 0.000145 & 0.001121 & 0.003120 & 4.65 \\
\hline 300 & 3.3527 & 0.000672 & 0.001923 & 0.007362 & 9.13 \\
\hline 400 & 6.7956 & 0.002587 & 0.004855 & 0.025291 & 10.23 \\
\hline 500 & 17.3264 & 0.009421 & 0.011364 & 0.049520 & 19.02 \\
\hline 600 & 11.3059 & 0.005092 & 0.007815 & 0.031547 & 16.14 \\
\hline 700 & 4.9532 & 0.000651 & 0.002454 & 0.031457 & 20.69 \\
\hline
\end{tabular}
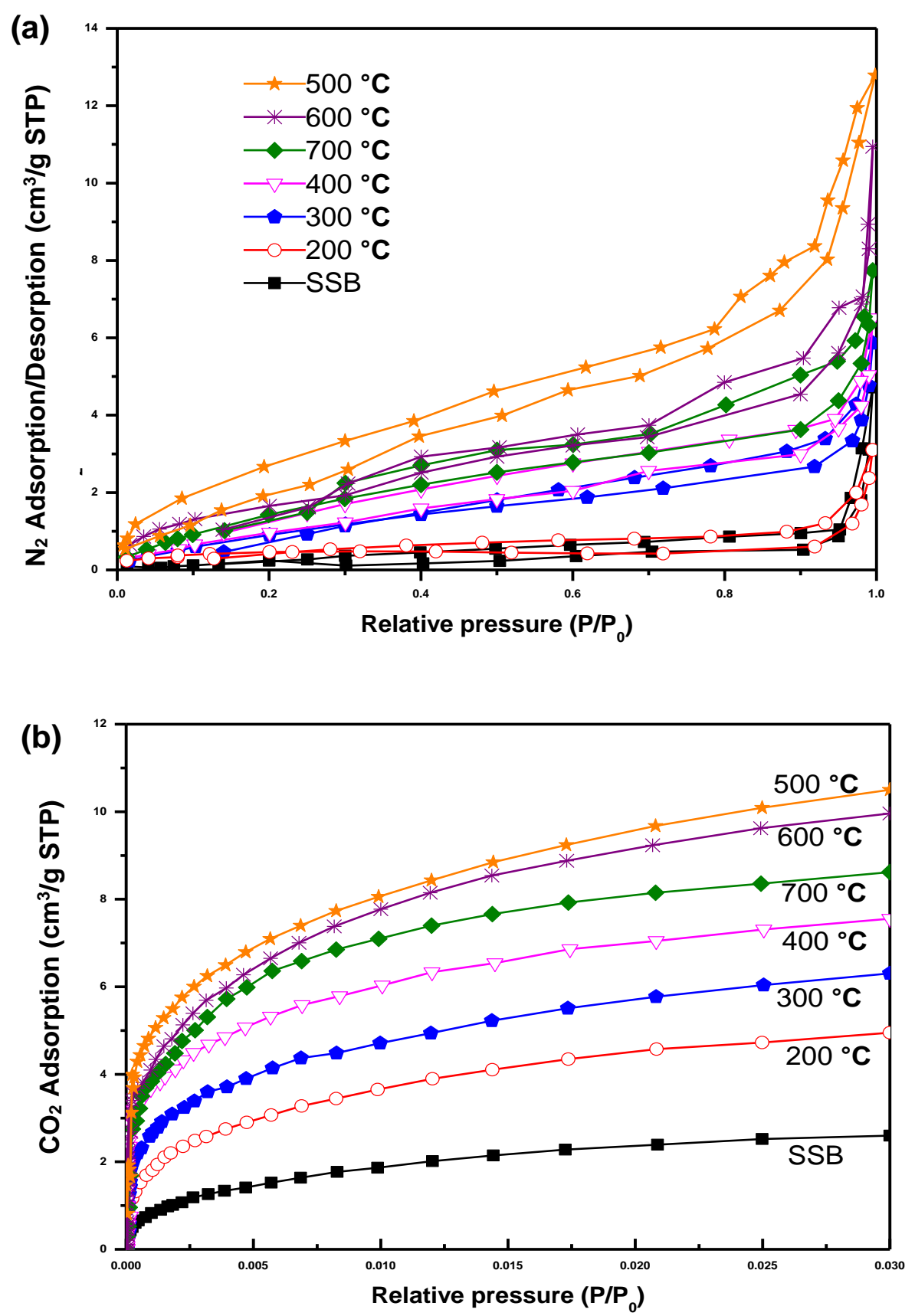

Fig. 6. Adsorption isotherms of SSB and SSBB prepared at different pyrolysis temperatures: (a) $\mathrm{N}_{2}$ adsorption/desorption isotherms and (b) $\mathrm{CO}_{2}$ adsorption isotherms 
Recently, the adsorption/desorption of low-pressure gas has been widely used for the pore structure characteristics analysis. Figure 6 shows the adsorption isotherms of SSB and SSBB prepared at different pyrolysis temperatures. As shown in Fig. 6(a), the adsorption/desorption curves of SSB and different SSBB samples were similar and presented an inverse S-shape. According to Brunauer-Deming-Deming-Teller (BDDT) classification, the curves were similar to type II isotherms (Brunauer et al. 1938), indicating that SSB and SSBB had a complex pore structure system and the pore size distribution was continuous. The initial part of the curves rose slowly and presented an upward convex shape, indicating the transition of adsorption from monolayer to multimolecular layer. The second half of the curves sharply rose and presented no adsorption saturation while the relative pressure reached 1.0, which was consistent with capillary condensation in the pore structure of SSBB. In contrast, the curve of SSB and the curve of $200{ }^{\circ} \mathrm{C} \mathrm{SSBB}$ were intertwined with each other, and there was no obvious distinction between them. This further demonstrated that the loss of water had little effect on the pore structure characteristics of SSBB. It should be noted that with the increase of pyrolysis temperature, the $\mathrm{N}_{2}$ adsorption/desorption capacity of SSBB increased first and then decreased, and it reached the maximum at $500{ }^{\circ} \mathrm{C}$, indicating that with the increase of the pyrolysis temperature, the pore structure of SSBB was more developed and the adsorption amount was larger, while the higher temperatures $\left(600,700{ }^{\circ} \mathrm{C}\right)$ could cause the collapse and decomposition of SSB and decrease the $\mathrm{N}_{2}$ adsorption/desorption capacity. As observed in Fig. 6 (b), the effects of pyrolysis temperature on the $\mathrm{CO}_{2}$ adsorption of SSBB were consistent with that of $\mathrm{N}_{2}$ adsorption/desorption. Above all, the changes of the pore structure characteristics were consistent with SEM analysis of SSBB, which further confirmed the evolution of SSBB under different pyrolysis temperature.

\section{CONCLUSIONS}

1. The objective of this study was to determine the evolution of biochar structural features during fast pyrolysis of sweet sorghum bagasse in a novel $\mathrm{V}$-shaped down tube reaction device within a temperature range of 200 to $700{ }^{\circ} \mathrm{C}$. The results showed that pyrolysis temperature had an important effect on the composition and physicochemical properties of sweet sorghum bagasse biochar, and the biochar obtained at $500{ }^{\circ} \mathrm{C}$ had the most developed pore structure.

2. The information attained herein is of great importance for the utilization of sweet sorghum bagasse obtained from the advanced solid-state fermentation.

\section{ACKNOWLEDGEMENTS}

The authors gratefully thank the support for this research from The National Natural Science Foundation of China $(51536009,51276103)$, The Natural Science Foundation of Shandong Province of China (ZR2019MEE036), and the Distinguished Expert of Taishan

Scholars Shandong Province, Higher Education Superior Discipline Team Training Program of Shandong Province. 


\section{REFERENCES CITED}

Abnisa, F., and Daud, W. M. A. W. (2014). "A review on co-pyrolysis of biomass: An optional technique to obtain a high-grade pyrolysis oil," Energy Conversion and Management 87, 71-85. DOI: 10.1016/j.enconman.2014.07.007

Al-Wabel, M. I., Al-Omran, A., El-Naggar, A. H., Nadeem, M., and Usman, A. R. (2013). "Pyrolysis temperature induced changes in characteristics and chemical composition of biochar produced from conocarpus wastes," Bioresource Technology 131, 374-379. DOI: 10.1016/j.biortech.2012.12.165

Alvarez, J., Lopez, G., Amutio, M., Bilbao, J., and Olazar, M. (2014). "Upgrading the rice husk char obtained by flash pyrolysis for the production of amorphous silica and high quality activated carbon," Bioresource Technology 170, 132-137. DOI: 10.1016/j.biortech.2014.07.073

Angin, D. (2013). "Effect of pyrolysis temperature and heating rate on biochar obtained from pyrolysis of safflower seed press cake," Bioresource Technology 128, 593-597. DOI: 10.1016/j.biortech.2012.10.150

Antal, M. J. J., and Varhegyi, G. (1995). "Cellulose pyrolysis kinetics: The current state of knowledge," Industrial \& Engineering Chemistry Research 34(3), 703-717. DOI: 10.1021/ie00042a001

Boakye-Boaten, N. A., Xiu, S., Shahbazi, A., Wang, L., Li, R., and Schimmel, K. (2016). "Uses of miscanthus press juice within a green biorefinery platform," Bioresource Technology 207, 285-292. DOI: 10.1016/j.biortech.2016.02.030

Brunauer, S., Emmett, P. H., and Teller, E. (1938). "Adsorption of gases in multimolecular layers," Journal of the American Chemical Society 60(2), 309-319. DOI: $10.1021 / \mathrm{ja} 01269 \mathrm{a} 023$

Cardoso, C., Miranda, M., Santos, K., and Ataíde, C. (2011). "Determination of kinetic parameters and analytical pyrolysis of tobacco waste and sorghum bagasse," Journal of Analytical and Applied Pyrolysis 92(2), 392-400. DOI: 10.1016/j.jaap.2011.07.013

Chen, G., Yao, J., Liu, J., Yan, B., and Shan, R. (2016). "Biomass to hydrogen-rich syngas via catalytic steam reforming of bio-oil," Renewable Energy 91, 315-322. DOI: 10.1016/j.renene.2016.01.073

Chen, H., Liu, D., Shen, Z., Bao, B., Zhao, S., and Wu, L. (2015). "Functional biomass carbons with hierarchical porous structure for supercapacitor electrode materials," Electrochimica Acta 180, 241-251. DOI: 10.1016/j.electacta.2015.08.133

Chen, T., Wu, C., Liu, R., Fei, W., and Liu, S. (2011). "Effect of hot vapor filtration on the characterization of bio-oil from rice husks with fast pyrolysis in a fluidized-bed reactor," Bioresour. Technol. 102(10), 6178-6185. DOI: 10.1016/j.biortech.2011.02.023

Fatehi, H., and Bai, X.-S. (2017). "Structural evolution of biomass char and its effect on the gasification rate," Applied Energy 185, 998-1006. DOI: 10.1016/j.apenergy.2015.12.093

Fatriasari, W., and Iswanto, A. H. (2015). "The kraft pulp and paper properties of sweet sorghum bagasse (Sorghum bicolor L Moench)," Journal of Engineering \& Technological Sciences 47(2). DOI: 10.5614/j.eng.technol.sci.2015.47.2.4 
Fu, P., Bai, X., Yi, W., Li, Z., and Li, Y. (2018). "Fast pyrolysis of wheat straw in a dual concentric rotary cylinder reactor with ceramic balls as recirculated heat carrier," Energy Conversion and Management 171, 855-862. DOI: 10.1016/j.enconman.2018.06.035

Fu, P., Hu, S., Xiang, J., Sun, L., Su, S., and Wang, J. (2012). "Evaluation of the porous structure development of chars from pyrolysis of rice straw: Effects of pyrolysis temperature and heating rate," Journal of Analytical and Applied Pyrolysis 98, 177 183. 10.1016/j.jaap.2012.08.005

Fu, P., Yi, W., Li, Z., Bai, X., and Wang, L. (2017). "Evolution of char structural features during fast pyrolysis of corn straw with solid heat carriers in a novel V-shaped down tube reactor," Energy Conversion and Management 149, 570-578. DOI: 10.1016/j.enconman.2017.07.068

Fu, P., Yi, W., Li, Z., and Li, Y. (2019). "Comparative study on fast pyrolysis of agricultural straw residues based on heat carrier circulation heating," Bioresource Technology 271, 136-142. DOI: 10.1016/j.biortech.2018.09.099

Houx, J. H., Roberts, C. A., and Fritschi, F. B. (2013). "Evaluation of sweet sorghum bagasse as an alternative livestock feed," Crop Science 53(4), 1784-1790. DOI: 10.2135/cropsci2012.03.0190

Junshe, L. L. S., and Ping, K. L. L. (2007). "The Fuel ethanol production from sweet sorghum stalk," Progress in Chemistry, Z2.

Keiluweit, M., Nico, P. S., Johnson, M. G., and Kleber, M. (2010). "Dynamic molecular structure of plant biomass-derived black carbon (biochar)," Environmental Science \& Technology 44(4), 1247-1253. DOI: 10.1021/es9031419

Kim, K. H., Kim, J.-Y., Cho, T.-S., and Choi, J. W. (2012). "Influence of pyrolysis temperature on physicochemical properties of biochar obtained from the fast pyrolysis of pitch pine (Pinus rigida)," Bioresource Technology 118, 158-162. DOI: 10.1016/j.biortech.2012.04.094

Kloss, S., Zehetner, F., Dellantonio, A., Hamid, R., Ottner, F., Liedtke, V., Schwanninger, M., Gerzabek, M. H., and Soja, G. (2012). "Characterization of slow pyrolysis biochars: Effects of feedstocks and pyrolysis temperature on biochar properties," Journal of Environmental Quality 41(4), 990-1000. DOI: 10.2134/jeq2011.0070

Li, S., Li, G., Zhang, L., Zhou, Z., Han, B., Hou, W., Wang, J., and Li, T. (2013). "A demonstration study of ethanol production from sweet sorghum stems with advanced solid state fermentation technology," Applied Energy 102, 260-265. DOI: 10.1016/j.apenergy.2012.09.060

Li, Z., Li, N., Yi, W., Fu, P., Li, Y., and Bai, X. (2017). "Design and operation of a down-tube reactor demonstration plant for biomass fast pyrolysis," Fuel Processing Technology 161, 182-192. DOI: 10.1016/j.fuproc.2016.12.014

Ma, K., Ruan, Z., Shui, Z., Wang, Y., Hu, G., and He, M. (2016). "Open fermentative production of fuel ethanol from food waste by an acid-tolerant mutant strain of Zymomonas mobilis," Bioresource Technology 203, 295-302. DOI: 10.1016/j.biortech.2015.12.054

Ma, Z., Chen, D., Gu, J., Bao, B., and Zhang, Q. (2015). "Determination of pyrolysis characteristics and kinetics of palm kernel shell using TGA-FTIR and model-free integral methods," Energy Conversion and Management 89, 251-259. DOI: 10.1016/j.enconman.2014.09.074 
Naik, D. K., Monika, K., Prabhakar, S., Parthasarathy, R., Satyavathi, B. (2017). "Pyrolysis of sorghum bagasse biomass into bio-char and bio-oil products," Journal of Thermal Analysis and Calorimetry 127(2), 1277-1289. DOI: 10.1007/s10973-0166061-y

Nanda, S., Dalai, A. K., Berruti, F., and Kozinski, J. A. (2016). "Biochar as an exceptional bioresource for energy, agronomy, carbon sequestration, activated carbon and specialty materials," Waste and Biomass Valorization 7(2), 201-235. DOI: 10.1007/s12649-015-9459-z

Rafiq, M. K., Bachmann, R. T., Rafiq, M. T., Shang, Z., Joseph, S., and Long, R. (2016). "Influence of pyrolysis temperature on physico-chemical properties of corn stover (Zea mays L.) biochar and feasibility for carbon capture and energy balance," PloS one 11(6), e0156894. DOI: 10.1371/journal.pone.0156894

Sharma, R. K., Wooten, J. B., Baliga, V. L., Lin, X., Chan, W. G., and Hajaligol, M. R. (2004). "Characterization of chars from pyrolysis of lignin," Fuel 83(11-12), 14691482. DOI: 10.1016/j.fuel.2003.11.015

Spokas, K. A., Baker, J. M., and Reicosky, D. C. (2010). "Ethylene: Potential key for biochar amendment impacts," Plant and Soil 333(1-2), 443-452. DOI: 10.1007/s11104-010-0359-5

Tan, Y., Abdullah, A., and Hameed, B. (2017). "Fast pyrolysis of durian (Durio zibethinus L) shell in a drop-type fixed bed reactor: Pyrolysis behavior and product analyses," Bioresource Technology, 243, 85-92. DOI: 10.1016/j.biortech.2017.06.015

Thangalazhy-Gopakumar, S., Al-Nadheri, W. M. A., Jegarajan, D., Sahu, J., Mubarak, N., and Nizamuddin, S. (2015). "Utilization of palm oil sludge through pyrolysis for bio-oil and bio-char production," Bioresource Technology 178, 65-69. DOI: 10.1016/j.biortech.2014.09.068

Uchimiya, M., Wartelle, L. H., Klasson, K. T., Fortier, C. A., and Lima, I. M. (2011). Influence of pyrolysis temperature on biochar property and function as a heavy metal sorbent in soil," Journal of Agricultural and Food Chemistry 59(6), 2501-2510. DOI: $10.1021 / \mathrm{jf} 104206 \mathrm{c}$

Vamvuka, D., and Sfakiotakis, S. (2011). "Effects of heating rate and water leaching of perennial energy crops on pyrolysis characteristics and kinetics," Renewable Energy, 36(9), 2433-2439. DOI: 10.1016/j.renene.2011.02.013

Wang, Z., Cao, J., and Wang, J. (2009). "Pyrolytic characteristics of pine wood in a slowly heating and gas sweeping fixed-bed reactor," Journal of Analytical and Applied Pyrolysis 84(2), 179-184. DOI: 10.1016/j.jaap.2009.02.001

Yin, R., Liu, R., Mei, Y., Fei, W., and Sun, X. (2013). "Characterization of bio-oil and bio-char obtained from sweet sorghum bagasse fast pyrolysis with fractional condensers," Fuel 112, 96-104. DOI: 10.1016/j.fuel.2013.04.090

Yuan, J.-H., Xu, R.-K., and Zhang, H. (2011). "The forms of alkalis in the biochar produced from crop residues at different temperatures," Bioresource Technology 102(3), 3488-3497. DOI: 10.1016/j.biortech.2010.11.018

Zhang, J., Liu, J., and Liu, R. (2015). "Effects of pyrolysis temperature and heating time on biochar obtained from the pyrolysis of straw and lignosulfonate," Bioresource Technology 176, 288-291. DOI: 10.1016/j.biortech.2014.11.011

Zhang, J., Ma, X., Yu, J., Zhang, X., and Tan, T. (2011). "The effects of four different pretreatments on enzymatic hydrolysis of sweet sorghum bagasse," Bioresource Technology 102(6), 4585-4589. DOI: 10.1016/j.biortech.2010.12.093 
Zhang, Y., Ma, Z., Zhang, Q., Wang, J., Ma, Q., Yang, Y., Luo, X., and Zhang, W. (2017). "Comparison of the physicochemical characteristics of bio-char pyrolyzed from moso bamboo and rice husk with different pyrolysis temperatures," BioResources 12(3), 4652-4669. DOI: 10.15376/biores.12.3.4652-4669

Article submitted: October 31, 2019; Peer review completed: March 13, 2020; Revised version received: July 1, 2020; Published: July 9, 2020.

DOI: $10.15376 /$ biores. 15.3.6600-6616 